\title{
La clase obrera chilena durante la dictadura (1973-1989): transformaciones en su acción y estructura social
}

\author{
The Chilean working class during dictatorship (1973-1989): \\ transformations in its action and social structure
}

\author{
Giorgio Boccardo*
}

\begin{abstract}
Resumen:
Este artículo analiza las transformaciones en la acción y estructura social de la clase obrera chilena entre 1973 y 1989. Primero, se revisan antecedentes sobre la formación y desenvolvimiento de la clase obrera hasta 1973. Segundo, se analizan las principales transformaciones en la acción y fisonomía estructural de los obreros y sus organizaciones en dictadura. Se argumenta que entre 1973 y 1977, fracciones sindicales intentan una representación de los trabajadores ante la dictadura; en tanto, desde 1978, resisten las reformas neoliberales y sientan las bases de una oposición al régimen militar. Se concluye que la desarticulación de sus bases sociales, particularmente de la clase obrera industrial, y el modo en que se resuelve políticamente la transición le dificulta recuperar la fisonomía y poder alcanzados hasta 1973.
\end{abstract}

Palabras clave: clase obrera, sindicatos, conflicto, estructura social, dictadura.

\begin{abstract}
:
This article analyses the changes in the action and social structure of the Chilean working class between 1973 and 1989. First, it reviews the background of the formation and development of the working class until 1973. Second, it analyses the main transformations in the action and social structure of the workers and their organizations during dictatorship. It is argued that between 1973 and 1977, some of the trade unions tried to represent politically the workers before the dictatorship. Since 1978, trade unions tried to resist the neoliberal reforms and established the basis of an opposition to the military regime. Finally, it is concluded that the disarticulation of its social bases, particularly of the industrial working class, and the way in which the transition is politically solved, made it difficult for them to recover it's structure and power achieved until 1973.
\end{abstract}

Keywords: working class, trade unions, social conflict, social structure, dictatorship.

* Chileno, Sociólogo y académico del Departamento de Sociología en la Universidad de Chile. Correo electrónico: gboccardo@u.uchile.cl 
El carácter refundacional de la dictadura chilena no tiene parangón en el mundo entero. Las transformaciones neoliberales arrasan con buena parte de la fisonomía de clases y grupos sociales forjados en el periodo nacional-popular. En específico, entre 1973 y 1989 se produce un paulatino y conflictivo desarme de la clase obrera industrial y, a pesar de que algunos de sus sindicatos tienen una activa participación en las jornadas de protesta, durante la transición, los obreros pierden peso en la dirección política y cultural de la sociedad. En tanto, los partidos políticos que los organizaron renuevan sus idearios y se alejan de prácticas y discursos que alientan la lucha de clases. Pese a una crecida del malestar y de la huelga laboral en los últimos años ${ }^{1}$, sus expresiones manifiestas provienen de procesos de trabajo vinculados a los servicios y el comercio, o de las franjas más flexibilizadas en el sector primario exportador. Lo que altera significativamente las modalidades de organización y lucha forjadas por la clase obrera chilena hasta 1973. De ahí que resulte necesario indagar sobre los cursos de acción y las transformaciones que soportan los trabajadores bajo la dictadura militar.

Algunas interpretaciones han centrado la atención en la reestructuración industrial y en los cambios de las condiciones de vida de los obreros en dictadura ${ }^{2}$. Otras en cambio, han apuntado a la represión, tortura y desaparición de sus principales dirigentes $\mathrm{o}$ a la responsabilidad política de las élites partidarias durante la crisis de $1973^{3}$. Con el retorno de la democracia, se argumenta que el declive de los sindicatos y la renovación de las ideologías obreristas es parte de un cambio epocal vinculado a la globalización, al fin de las ideologías y de las clases sociales ${ }^{4}$; pero también, ha sido relacionado con la expansión del consumo, el endeudamiento y el individualismo que fomenta la doctrina neoliberal ${ }^{5}$.

Sin desconocer el valor de esas interpretaciones, las transformaciones estructurales que se ejecutan en dictadura no constituyen un derrotero lineal ni tampoco producen una recepción pasiva de las fuerzas sociales que se ven afectadas. De hecho, la implementación de las reformas neoliberales es posible a medida que va siendo derrotada políticamente la clase obrera industrial (y no al revés). Efectivamente, entre 1973 y 1989 diversas fracciones del movimiento obrero ensayan estrategias de representación y prácticas de resistencia que luego decantan en los movimientos de oposición a la dictadura ${ }^{6}$. No obstante, la atención prestada a su recuperación económica desde 1986 o a su activa participación como fuerza de apoyo en la transición han obnubilado la comprensión de los profundos cambios que esta clase experimentó en los años ochenta, al punto de no retornar en la escena social y política de la década del noventa.

1Dasten Julián, "Tendencias de un sindicalismo fracturado. Sindicalismo autoritario v/s sindicalismo movimientista", Actuel Marx Intervenciones, 13, 2012, 95-113.

2René Cortázar, "Políticas de reajustes y salarios en Chile: 1974-1982”, Colección Estudios, Cieplan, 10, 1983, 45-64; Álvaro Díaz, "La reestructuración industrial autoritaria en Chile", Revista Proposiciones, 17, 1989, 14-35. Paul Drake, "El movimiento obrero en Chile: De la Unidad Popular a la Concertación”, Revista de Ciencia Política (Santiago), 23:2, 2003, 148-158.

3Para una crítica a estos enfoques ver Rodrigo Baño, "Más allá de culpas y buenas intenciones", Rodrigo Baño, Unidad Popular 30 años después, Santiago, Lom Ediciones, 2003, 291-318.

4José Joaquín Brunner, Bienvenidos a la modernidad, Santiago, Editorial Planeta, 1994; Eugenio Tironi, La irrupción de las masas y el malestar de las élites. Chile en el cambio de siglo, Santiago, Editorial Grijalbo, 1999.

5Tomás Moulian, Chile actual: Anatomía de un mito, Santiago, Lom Ediciones, 1997.

6Rodrigo Araya, "Ha llegado la hora de decir basta. El movimiento sindical y la lucha por la democracia en Chile, 1973-1990", Izquierdas, 27, 2017, 191-211; Ana López, "El mundo del trabajo entre el disciplinamiento y la resistencia, Chile, 1973-1981", Procesos. Revista ecuatoriana de historia, 44, 2016, 75-101. 
El propósito de este artículo es explicar el declive de la clase obrera chilena a partir de los cambios que experimenta en su acción y estructura social entre 1973 y 1989. Se sostiene que la desarticulación de sus bases sociales, particularmente de la clase obrera industrial, y el modo en que se resuelve políticamente la transición le dificulta recuperar la fisonomía y poder alcanzados hasta 1973.

\section{La clase obrera chilena hasta 1973:}

\section{Estado, partidos políticos y heterogeneidad social}

Hasta la década del setenta del siglo XX, la clase obrera chilena se caracterizó por el peso de sus organizaciones sindicales a escala nacional y una militancia activa en partidos políticos. Pese a la abundancia de pequeños sindicatos, desde 1953, la Central Única de Trabajadores de Chile (CUT) fue su principal representante ante el Estado y las clases dominantes ${ }^{7}$. Sin embargo, al no contar con un reconocimiento institucional, su éxito dependió principalmente del signo político del gobierno de turno y de la capacidad de movilización de sus afiliados. Aunque la relación entre sindicatos y partidos políticos fue siempre conflictiva, los trabajadores se fueron organizando en el Partido Socialista (PS), el Partido Comunista (PC) y el Partido Radical (PR) y, posteriormente, en la Democracia Cristiana (DC). Aunque una fracción considerable del campo popular estaba integrado por trabajadores rurales y grupos marginales, su componente obrero fue distintivo en la dirección de la sociedad al punto de configurar la principal base de sustentación de la Unidad Popular (UP).

Otro elemento distintivo de los obreros hasta 1973 fue su heterogeneidad. Los diversos grados de industrialización alcanzados por la acción del Estado y de los capitales multinacionales, abren disímiles cursos de formación y desenvolvimiento de la clase obrera chilena ${ }^{8}$. En términos generales, en la gran industria sustitutiva y en la minería del cobre se consolida una clase obrera con mayor poder sindical y militancia política, y donde priman acciones redistributivas y una mayor aceptación de las estructuras de poder heredadas ${ }^{9}$. En cambio, en la mediana y pequeña industria, se organizan trabajadores menos calificados, con mayores dificultades para sindicalizarse y una menor participación en partidos, primando una acción directa que crecientemente desbordó la frágil institucionalidad alcanzada en el Chile nacional-popular. De todas formas, ambas fracciones del movimiento obrero tuvieron que recurrir permanentemente a la movilización, el paro y la huelga para alcanzar sus objetivos.

Ahora bien, en la experiencia chilena se agota tempranamente un sindicalismo autónomo de la acción estatal, como el forjado en la industria del salitre a finales del XIX ${ }^{10}$, siendo desplazado por otro que apuntó a su integración en el Estado. En efecto, pese a que durante la década del cincuenta la CUT, liderada por Clotario Blest, mantiene cierta posición de autonomía de los gobiernos de turno, hacia 1961 el PC retoma el control de la central y, en

7Alan Angell, Partidos politicos y movimiento obrero en Chile. Ediciones Era, 1974.

8Sergio Aranda y Alberto Martínez, "Estructura Económica: algunas características fundamentales", CESO, Chile, hoy, Santiago, Siglo XXI Editores, 1970, 55-172.

9Enzo Faletto y Eduardo Ruiz, "Conflicto político y estructura social", CESO, Chile, hoy, Santiago, Editorial Siglo XXI, 1970, 213-254.

10Sergio Grez, De la" regeneración del pueblo" a la huelga general: génesis y evolución histórica del movimiento popular en Chile (1810-1890), Santiago, RIL Editores, 2007. 
disputa con demócrata cristianos y socialistas, apuestan por la construcción de gobiernos populares ${ }^{11}$.

Las condiciones de formación de la clase obrera chilena durante el siglo XX se producen mayoritariamente a partir de la acción estatal y su origen es principalmente campesino. Esto permite que en la industria y minería se desenvuelvan prácticas de control autoritarias importadas del modo de dominio hacendal ${ }^{12}$. Efectivamente, hasta comienzos de la década del sesenta predominan mecanismos de control paternalista y sistemas de reclutamiento que buscaron asegurar la lealtad patronal, lo cual dificultó la organización de sindicatos autónomos ${ }^{13}$. De todos modos, las protestas les permiten a estos trabajadores obtener mejores salarios y seguridad social que los alcanzados por del resto de las fuerzas populares. No obstante, tales mejoras desatan la reacción de algunos empresarios que incorporan técnicas de racionalización para elevar la producción y reducir el costo de la fuerza de trabajo.

La introducción de métodos tayloristas en la minería y en la gran industria moderna activan una reacción más articulada de los trabajadores, como ocurre en el paro de la minera Andes Cooper en $1961^{14}$ o la huelga de la textil Yarur en $1962^{15}$. Son movilizaciones contra la pérdida del empleo, la mayor intensidad del trabajo, salarios vinculados a productividad y la introducción de mecanismos de flexibilidad. Para los antiguos trabajadores significó el declive de las relaciones patronales de producción y del bienestar alcanzado en esa etapa; en tanto, las nuevas generaciones, formadas en barrios obreros organizados por los partidos nacional populares, estaba menos dispuestas a aceptar mecanismos de control y organizaciones sindicales impuestas por la patronal. Y si bien, sus fracciones más radicalizadas sientan las bases de un sindicalismo que intenta autonomizarse de la UP como ocurre, por ejemplo, en los cordones industriales en Santiago o Concepción ${ }^{16}$; en lo fundamental, la clase obrera chilena presionó, sobre todo desde 1965 en adelante, por una mejora sustantiva de sus remuneraciones ${ }^{17}$ y por su incorporación en la institucionalidad política.

A medida que aumenta la concentración y burocratización de las grandes empresas estatales y de aquellas controladas por capitales extranjeros, se incrementan las ocupaciones de supervisión y control de la fuerza de trabajo. Estas nuevas posiciones de empleado, ocupadas en su mayoría por los obreros de mayor experiencia fruto de presión y negociaciones, generan cierta fragmentación en la configuración subjetiva de la clase obrera. En efecto, el mayor prestigio social y las mejores remuneraciones de estos empleados los aproximó en algunos casos a la "cultura mesocrática" de profesionales y técnicos que se desempeñaban en la misma fabrica $^{18}$. De todos modos, son condiciones que se reproducen principalmente en empresas de gran tamaño, mientras que en el resto de las ramas productivas primaron formas de

11Franck Gaudichaud, Chile 1970-1973. Mil días que estremecieron al mundo, Barcelona, Editorial Sylone, 2017.

12Francisco, Zapata, Clases sociales y acción obrera en Chile, México D.F., Colegio de México, Centro de Estudios Sociológicos, 110, 1986.

13Peter Winn, “El Taylorismo y la gran huelga de Yarur de 1962”, Proposiciones, 19, 1990, 202-222

14Ángela Vergara, "Conflicto y modernización en la Gran Minería del Cobre (1950-1970)", Historia, Santiago, 37:2, 2004, 419436.

15Winn, op. cit.

16Carlos Ruiz, "Reseña del libro de Eugenia Palieraki ¡La Revolución ya viene! El MIR chileno de los años sesenta”, Actuel Marx Intervenciones, 211-218.

17Entre 1965 y 1970 los salarios reales crecen a una tasa promedio anual de 10\%, en Cortázar, op. cit.

18Torcuato Di Tella y Alain Touraine, Huachipato et Lota. Étude sur la conscience ouvrière dans deux entreprises chiliennes, París, Centre National de la Recherche Scientifique de Paris (CNRS), 1966. 
paternalismo represivo y protestas obreras que apuntaron a mejorar condiciones elementales de trabajo ${ }^{19}$.

De todas formas, hasta 1973 se organizó una clase obrera moderna acotada, en relación al resto del campo popular, pero que constituye una de las fuerzas mejor organizada social y políticamente, al punto que devienen en pilar clave de la alianza nacional-popular ${ }^{20}$. No obstante, esta conflictiva incorporación de algunas fracción de la clase trabajadora deja fuera a otras fuerzas que desbordan el procesos político institucional ${ }^{21}$. En consecuencia, los intereses sociales y políticos de las diversas fracciones del campo popular se van distanciando, hasta articular cursos de acción diferentes, expresados en tendencias a la movilización o la negociación, y en grados de participación en los principales partidos políticos.

Estas diferencias, fraguadas por las propias limitaciones de la industrialización sustitutiva pero también por el derrotero de socialistas, comunistas y demócrata cristianos, generan una fractura en el campo popular ${ }^{22}$. Los obreros de la industria moderna y la "aristocracia minera" encabezada principalmente por el PC y la DC, se muestran más proclives a reformas graduales y a la negociación con algunas fracciones de la "clase media desarrollista". En cambio, los obreros de la pequeña y mediana industria encabezados por el ala radical del PS, en intermitentes alianzas con algunos grupos poblacionales organizados por el Movimiento de Acción Popular Unitaria (MAPU) y el Movimiento de Izquierda Revolucionario (MIR), presionan por radicalizar el programa de la UP sin transar con intereses de grupos medios y obreros que militan en la $\mathrm{DC}^{23}$.

En suma, es esta situación de masas que desborda el proceso de trabajo en las distintas ramas de la industria y en la gran minería del cobre y, a nivel político, a las conducciones de la UP, lo que dificulta orientar en alguna dirección coherente la "vía chilena al socialismo". En adelante, el quiebre de las fuerzas populares y de sus partidos se vuelve irreversible, al punto que la derrota del gobierno de Salvador Allende puede encontrarse en alguna medida en el contradictorio campo de fuerzas e intereses populares que lo apoyan. En consecuencia, es a partir de esta división que la acción del heterogéneo campo de fuerzas que respalda el golpe militar se torna efectiva.

19La dinámica política más favorable para los trabajadores en 1965-1973 permite un aumento de la huelga en empresas medianas y pequeñas. Oscar Mac-Clure, "La acción reivindicativa sindical en Chile", Proposiciones, 17, 1989, 110-123.

20Enzo Faletto, "La dependencia y lo nacional-popular", Nueva Sociedad, 40, enero-febrero 1979, 40-49.

21En 1971-1972 el número de trabajadores comprometidos en las huelgas legales disminuye de 41.343 a 12.986, en tanto, el número de trabajadores involucrados en las huelgas de carácter ilegal aumenta de 130.966 a 193.862. Alberto Armstrong y Beiza Águila, Evolución del conflicto laboral en Chile: 1961-2002, Santiago, Ediciones Universidad Católica de Chile, 2006. De todas formas, cabe señalar que las huelgas ilegales vienen aumentando en Chile desde la década del sesenta, producto de las propias limitaciones de la institucionalidad que regula las relaciones laborales.

22Baño, op. cit.

23Carlos Ruiz y Giorgio Boccardo, Los cbilenos bajo el neoliberalismo. Clases y conflicto social, Santiago, El Desconcierto-Fundación Nodo XXI, 2014. 


\section{La clase obrera en dictadura: desarticulación, intentos de representación, resistencia y oposición} (1973-1989)

Los cambios ocurridos en la clase obrera chilena desde 1973 son de una hondura sin parangón en América Latina. A diferencia de lo ocurrido en países como Argentina o Brasil, en que los sindicatos obreros enfrentan y morigeran muchas de las reformas neoliberales ${ }^{24}$; en Chile, bajo dictadura se imponen una serie de transformaciones en la producción y el trabajo que, pese a la resistencia de las organizaciones sindicales, terminan por arrasar con la fisonomía de clases y grupos sociales forjada en el periodo nacional-popular.

\section{Sindicalismo e intentos de representación en dictadura (1973-1977)}

Tras la derrota de la UP en 1973 se inicia un periodo de dura represión sobre los trabajadores ${ }^{25}$ y sindicatos liderados por socialistas y comunistas, lo que impacta negativamente en las organizaciones de trabajadores ${ }^{26}$. Pero no ocurre tamaña coacción sobre algunas dirigencias sindicales demócrata cristianas y radicales que apoyaron el golpe y mantienen una posición de colaboración en los primeros años de la dictadura. En efecto, pese a que la CUT es proscrita y los derechos de huelga y negociación colectiva son suspendidos, por medio de la Fuerza Aérea de Chile (FACH), la Junta Militar intenta restablecer una legislación de carácter corporativista, en colaboración con dirigentes sindicales opositores a la UP ${ }^{27}$. Por un lado, los militares intentaban demostrar su eficacia para reactivar la economía nacional y, de paso, mejorar su alicaída imagen internacional en materia de derechos humanos; por otro, algunos sindicatos esperaban recuperar parte de los derechos laborales perdidos y la representación de los trabajadores asalariados.

En 1974, el Ministerio del Trabajo, liderado por la FACH, realiza un intento por institucionalizar las relaciones laborales mediante cuatro proyectos de ley ${ }^{28}$. El objetivo de las nuevas normativas era la formación de un sindicalismo afín al régimen, pero alejado de los partidos políticos marxistas. El ministro Díaz, apuesta por una alianza con los sindicatos demócrata cristianos de la gran minería e industria sustitutiva, pero también con nuevas fracciones sindicales de orientación gremialistas vinculadas al comercio, a grupos profesionales y al sector bancario ${ }^{29}$. En línea con esfuerzos desarrollados por otras dictaduras militares en

24Giorgio Boccardo, "Cambios recientes en la estructura social de Argentina, Brasil y Chile 1980-2010)", Entramados y perspectivas, 2, 2014, 43-70.

25Según el informe de la Comisión Nacional sobre Prisión Política y Tortura unas 8.206 personas (30,1\%) de los casos analizados eran trabajadores calificados, empleados, trabajadores de servicios públicos e industria y 5.681 personas (20,8\%) eran obreros industriales no calificados y de la construcción, trabajadores del comercio y los servicios.

26Hasta 1977 se consignaban 7.077 sindicatos y 916.472 afiliados, en 1979 hay 581.483 afiliados y 5.000 sindicatos y en 1983 solo 320.903 afiliados y 4.401 sindicatos, en Guillermo Campero, "El sindicalismo chileno en el régimen militar (1973-1984)", Ibero-Americana: Nordic Journal of Latin American Studies, 14, 1985, 175-188.

27Araya op. cit.

28Un nuevo código del trabajo, una ley general de cooperativas, un Estatuto social de la Empresa y un Estatuto de Seguridad Social. Sin embargo, solo la ley de cooperativas y el Estatuto Social se tornan ley, y sólo la primera se aplica luego de su dictación, en Campero, op. cit.

29Campero, op. cit. 
América Latina, estas medidas constituyeron un intento por reactivar la producción industrial nacional y frenar el espiral inflacionario.

Hacia 1975, los sectores nacionalistas e industriales que integraban la Junta Militar pierden peso ante los grupos "neoliberales" formados por abogados gremialistas, economistas monetaristas de la Escuela de Chicago e ingenieros que diseñan e implementan los principios de subsidiariedad estatal ${ }^{30}$. En adelante, se ejecutan una serie de políticas que apuntan a la reducción de aranceles, la liberalización del comercio y del sistema financiero, además de una privatización de la estructura productiva ${ }^{31}$. En el corto plazo, tales medidas generaron una drástica caída de los salarios, un aumento de los precio de la canasta básica y un mayor desempleo $^{32}$, lo que detona las protestas de las organizaciones sindicales que apostaban a una renovación ideológica de los trabajadores desde una posición marxista a otra socialcristiana. Sin embargo, en el mediano plazo, las reformas estructurales abren cauces a una privatización y desindustrialización de la estructura productiva ${ }^{33}$, y a una rápida expansión del sector primario exportador y financiero. En tanto, la incapacidad del empresariado industrial de contener la drástica apertura y de competir sin los apoyos estatales contra los productos importados termina por afectar las condiciones de reproducción de los propios obreros industriales.

El arribo de José Piñera al Ministerio del Trabajo marca el inicio de un nuevo diseño institucional en material laboral. En 1978 se deroga la Ley de Inamovilidad que obligaba a justificar los despidos e impone la figura del "desahucio" con una indemnización por años de antigüedad. En 1979, un nuevo Plan Laboral busca institucionalizar la acción futura de los trabajadores organizados, favoreciendo una orientación corporativa acotada a los límites de la empresa $^{34}$. El nuevo Código del Trabajo reduce las relaciones entre los sindicatos y el Estado, forzando negociaciones entre las empresas y pequeños sindicatos o grupos negociadores con escaso poder, lo que disminuye el peso estratégico de las federaciones, confederaciones o centrales nacionales sobre la dirección general de la sociedad ${ }^{35}$.

En definitiva, el nuevo orden institucional que regula las relaciones laborales prescinde del Estado como el principal espacio de procesamiento de conflictos entre empleadores y trabajadores, y reduce la existencia de los sindicatos a los límites de la unidad productiva y a demandas exclusivamente salariales, siendo considerado el trabajo mismo un recurso productivo más.

\section{Resistencia sindical a las reformas estructurales y formación de una oposición abierta a la dictadura (1978-1989)}

Las reformas neoliberales en material laboral van modificando la orientación del sindicalismo que resiste la dictadura. El rechazo al nuevo Código Laboral de 1979 es

30Ruiz y Boccardo, op. cit.

31Alejandro Foxley, “Hacia una economía de libre mercado: 1974-1979”, Revista de Estudios, Cieplan, 4, 1981, 5-37.

32Patricio Frías, El Trabajo ¿ Servidumbre o realización?, Santiago, Ediciones Radio Universidad de Chile, 2017.

33De todos modos, desde 1986 se produce una recuperación del empleo industrial, pero más allá de la estimación de los pesos cuantitativos de los obreros esto no significa mecánicamente un retorno de la clase obrera industrial en tanto fuerza social organizada, en Díaz, op. cit.

34José Piñera, La revolución laboral en Chile, Santiago, Zig-Zag, 1992.

35Irene Rojas, "Las reformas laborales al modelo normativo de negociación colectiva del Plan Laboral", Ius et Praxis, Talca, 13:2, 2007, 195-221. De todas formas, en el periodo 1932-1973 no existe formalmente negociación ramal, sino que acuerdos de tarifado en amas productivas específicas o aquellos alcanzados entre la CUT y el gobierno de turno, en Mac-Clure, op.cit. 
encabezado por el "Grupo de los 10" integrado por dirigente de sectores moderados de la DC y el radicalismo, y que inicialmente apostaron por una apertura de la actividad sindical autónoma y, de ese modo, evitar la rearticulación obrera marxista ${ }^{36}$. En tanto, la Coordinadora Nacional Sindical (CNS) junto con el pequeño Frente Unitario de Trabajadores (FUT) -que aglutinaban a otros sectores demócrata cristianos, a socialistas y comunistas-, se esfuerzan por revivir la unidad sindical de la CUT y representar una oposición a la dictadura y sus reformas laborales, que a esas alturas eran vistas como un ataque frontal a las condiciones de vida de los trabajadores ${ }^{37}$. La arremetida neoliberal fuerza a las distintas organizaciones sindicales a formar el Comité de Defensa de los Derechos Sindicales integrado por la CNS y el Grupo de los Diez que pasó a llamarse Unión Democrática de Trabajadores (UDT).

La Reforma al Sistema de Pensiones, iniciado a fines de 1980, y la nueva política social implementada por la Oficina de Planificación Nacional (Odeplan) vienen a coronar el orden neoliberal en materia de trabajo. En adelante, las cotizaciones para la jubilación serían individuales y el gasto social estaría focalizado en los "verdaderos pobres", excluyendo a miles de empleados y obreros del salario social alcanzado tras décadas de movilización. Se trataba de los primeros intentos de la dictadura por construir un "pinochetismo popular": los trabajadores serían "propietarios" de las empresas en que sus ahorros fueran invertidos y el emprendimiento alentado por el Estado sentaría las bases de una nueva clase empresarial que no dependería de las protecciones estatales.

A comienzos de los ochenta, sin embargo, no había atisbos de recuperación económica. Por el contrario, la inflación y el desempleo ${ }^{38}$ estaban carcomiendo las condiciones de vida de los trabajadores. Ahora bien, el problema de fondo era otro: las reformas neoliberales apuntaban a una radical transformación de los principios de solidaridad construidos por los sindicatos. En el largo plazo, la reproducción de los trabajadores dependería cada vez más de su esfuerzo individual y capacidad de acceso a los nuevos mercados de servicios sociales, por lo que la organización sindical y los partidos políticos comenzarían a perder su sentido práctico.

A medida de las reformas estructurales avanzaban, la oposición sindical se incrementó. Entre 1979 y 1982 se producen una serie de huelgas en la minería del cobre y el carbón, en la empresa metalúrgica de Madeco, en las textiles Victoria y el Panal, y en las empresas Sumar Nylon y Vinex ${ }^{39}$. Al terminar el año 1982, y fuera de los límites impuestos por el nuevo Código Laboral, los trabajadores de la central hidroeléctrica Colbún-Machicura realizan un paro por los bajos sueldos y el maltrato laboral, pero además sus reclamos constituyen el primer antecedente de lo serán las negociaciones inter-empresas y la lucha de los trabajadores subcontratados contra las desiguales condiciones de trabajo que enfrentan con relación a los trabajadores de planta ${ }^{40}$.

Todas estas transformaciones se expresan en cambios en la estructura social de la clase obrera chilena. Efectivamente, entre 1971 y 1982 el peso relativo de los obreros en la sociedad disminuye de un 34,5 a un $24,4 \%$ (Cuadro 1).

36Campero, op. cit.

37Araya, op. cit.

38Cortázar, op. cit. Se estima que en 1984 la tasa de desempleo abierto era de aproximadamente 24\%; sin embargo, si se agregan los programas estatales esta se eleva al 30\%, en Campero, op.cit.

39López, op. cit.

40Entrevista a José Villegas, Presidente Sindicato Colbún-Machicura, en Revista Apsi, 117, 25 de enero al 7 de febrero, $1983,8$. 
Cuadro 1: Significación numérica de la clase obrera 1971-1989

(en porcentaje de la PEA nacional y en número de personas).

\begin{tabular}{l|c|c|c|c|c|c|c}
\hline Grupo obrero & $\mathbf{1 9 7 1}$ & $\mathbf{1 9 8 0}$ & $\mathbf{1 9 8 2}$ & $\mathbf{1 9 8 6}$ & $\mathbf{1 9 8 7}$ & $\mathbf{1 9 8 8}$ & $\mathbf{1 9 8 9}$ \\
\hline \multirow{2}{*}{ Minería } & 1,30 & 1,27 & 0,93 & 0,72 & 0,76 & 0,73 & 1,07 \\
\cline { 2 - 8 } & 38.400 & 46.300 & 34.100 & 30.680 & 33.220 & 33.400 & 49.920 \\
\hline \multirow{3}{*}{ Industria y Construcción } & 25,80 & 11,11 & 7,51 & 10,00 & 11,39 & 11,99 & 12,70 \\
\cline { 2 - 8 } & 762.600 & 404.100 & 275.600 & 426.940 & 496.120 & 545.860 & 593.600 \\
\hline \multirow{3}{*}{ Comercio y Servicios } & 7,40 & 12,00 & 10,54 & 11,87 & 11,65 & 12,80 & 12,65 \\
\cline { 2 - 8 } & 218.700 & 437.500 & 386.800 & 506.800 & 507.420 & 582.790 & 591.320 \\
\hline \multirow{3}{*}{ Total } & 34,50 & 24,40 & 18,98 & 22,58 & 23,81 & 25,52 & 26,41 \\
\cline { 2 - 8 } & 1.019 .700 & 887.900 & 696.500 & 964.420 & 1.036 .760 & 1.162 .050 & 1.234 .840 \\
\hline
\end{tabular}

Fuente: Elaboración propia a partir de Encuesta Nacional de Empleo (ENE), trimestre octubre-diciembre, del Instituto Nacional de Estadísticas (INE) ${ }^{41}$.

El cambio más relevante es la drástica reducción que experimenta la clase obrera industrial y de la construcción (Cuadro 1). Entre 1971 y 1982 los obreros industriales disminuyen dramáticamente su peso relativo de 25,8 a 7,5\% (cerca de 487.000 trabajadores). Sin embargo, esta desindustrialización no sólo reduce el peso cuantitativo de los obreros industriales en la sociedad, sino que inicia la desarticulación de una de las fuerzas populares mejor organizada sindical y políticamente.

A diferencia de los obreros industriales, los mineros mantienen con oscilaciones su tamaño relativo en la estructura social en torno al 1\% (Cuadro 1). Esto último, producto del peso estratégico que la minería significa para la economía chilena y por el papel jugado por sus dirigentes. Efectivamente, desde 1978 sus sindicatos encabezan diversas protestas que van convergiendo con otras huelgas de trabajadores producto de la pauperización de las condiciones laborales a nivel general. En tanto, los trabajadores del comercio y de los servicios comienzan a expandir su tamaño relativo y absoluto en la estructura social (Cuadro 1), aunque para la crisis de 1982-1983 se verán igualmente afectados y varias de sus organizaciones sindicales terminarán por alejarse de su posición de apoyo irrestricto a la dictadura.

La incapacidad de la dictadura para sacar al país de la crisis económica se traduce en nuevos costos para los trabajadores. Mediante las leyes 18.134 y 18.198 se modifican los pisos mínimos para iniciar los procesos de negociación colectiva, alterando los criterios de reajuste salarial $^{42}$. A partir de estas leyes, los reajustes fueron por debajo del Índice de Precios al Consumidor agravando los procesos de precarización, informalidad o desempleo abierto a los que los trabajadores ya se encontraban sometidos. La ola de movilizaciones continúa con una Jornada Nacional de Protesta el 11 de Mayo de 1983 por la defensa al trabajo. Esta fue

41Son presentadas las estimaciones puntuales para cada año al cuál se le aplica el respectivo factor de expansión. El año 1982 y 1986 ya fueron publicados en Ruiz, op.cit. Para fines expositivos no se incorpora el intervalo de confianza ni los errores muestrales. Para 1971 y 1980 se presentan los datos de Eugenio Tironi y Javier Martínez, "Las clases sociales en Chile; cambio y estratificación 1970-1980", Santiago, Sur Ediciones, 1985. Salvo que se indique lo contrario, en adelante, todas las estimaciones puntuales presentadas provienen de la misma fuente.

42Ruiz y Boccardo, op. cit. 
encabezada por la Confederación de Trabajadores del Cobre (CNT) que era una de las pocas organizaciones sindicales que se mantenía incólume a los aparatos de represión de la dictadura.

La respuesta del gobierno militar fue, además de acrecentar la represión, fomentar la expansión de una economía campesina y de trabajadores por cuenta propia, además de la creación del Programa de Empleo Mínimo (PEM) y el Programa de Ocupación para Jefes de Hogar (POJH), esto es, una suerte de subempleo alentado por el Estado. Pese a que los ideólogos de la dictadura intentaron revestir a estos nuevos "emprendedores" como la base de un nuevo "capitalismo popular", son mayoritariamente trabajadores orientados a la sobrevivencia producto de las drásticas condiciones que les impone la crisis económica y las privatizaciones de los años ochenta.

Las convocatorias de los sindicatos confluyen con otros grupos populares durante las Jornadas de Protesta en 1983-1984, que constituyen el primer desafío abierto contra la dictadura. No obstante, el temor a perder los puestos de trabajo mermó la convocatoria de los asalariados, no así de jóvenes desempleados, organizaciones de mujeres y de grupos marginales. De todas formas, el accionar de las organizaciones sindicales se entronca con las demandas de recuperación de la democracia de los partidos políticos de oposición. Efectivamente, en un esfuerzo de convergencia, forman el Comando Nacional de Trabajadores (CNT) en que participan dirigentes de militancia demócrata cristiana, comunista y de las distintas fracciones socialistas, así como las principales organizaciones sindicales, a saber, el CNS, el FUT y la UDT.

Las diferencias políticas que generaban las distintas estrategias para derrocar a la dictadura dividen a las organizaciones sindicales que participan del Comando. En particular, los sectores más conservadores de la DC apuestan por una salida negociada con el régimen militar, lo que motiva la salida de la $\mathrm{UDT}^{43}$. De todas formas, el CNT apuesta por la movilización y representación del conjunto de los sectores populares, presentando los "Pliegos de Chile" en 1984-1985 y apoyando públicamente a la Asamblea de la Civilidad en 1986. Ahora bien, el problema de fondo para esos miles de obreros que se movilizaban en las calles era que sus puestos de trabajo desaparecían junto con toda una generación de empresarios desarrollistas. En suma, podían sobrevivir sus dirigentes, e incluso sus sindicatos, pero las bases sustentación de la clase obrera industrial se desestructuraban con los sucesivos cursos de desindustrialización y reindustrialización que experimentaba la estructura productiva nacional ${ }^{44}$.

\section{Cambios estructurales en la composición de la clase obrera (1971-1989)}

La recuperación económica iniciada en 1986, permite elevar sostenidamente las tasas de asalarización de todas las categorías obreras, incluida las industriales. No obstante, las fracciones que más rápidamente se expandieron son las ocupaciones terciarias que hacia 1989 representaban prácticamente el mismo tamaño absoluto que los obreros industriales y de la construcción (Cuadro 1). Justamente, las ramas del comercio y los servicios son las que absorben la gran mayoría de las nuevas ocupaciones obreras y, en adelante, se constituyen en el principal componente de los trabajadores asalariados. Ahora bien, el problema no se reduce

43Araya, op. cit.

44Díaz, op. cit. 
solamente a los cambios de tamaño de los principales componentes de la clase obrera, sino a una abrupta transformación de cada una de sus fracciones.

Al revisar los cambios en la fisonomía de los trabajadores de la minería entre 1980 y 1989, se observa un aumento de los trabajadores empleados en la pequeña y la mediana minería del cobre y de aquella no vinculada a éste, mientras que la gran minería del cobre disminuye significativamente su participación relativa (Cuadro 2). Los trabajadores de la gran minería del cobre, todavía mayoritariamente estatal, se verán afectado por el incremento de la automatización y externalización de funciones, pese a que mantendrán su poder de negociación y sus distintivos mecanismos de seguridad y bienestar.

Como se ha señalado, hasta 1973 el principal componente de la clase obrera chilena, pero también del resto de la estructura social, fueron los obreros industriales. Sin embargo, la privatización productiva y la desindustrialización producen un drástico descenso de éstos. Entre 1971 y 1982 disminuye significativamente su peso en la fuerza laboral nacional, y pese a su relativa recuperación en 1986-1989, esta viene acompañada de cambios importantes en su composición interna (Cuadro 2).

Cuadro 2: Composición interna clase obrera minera, industrial y de servicios en 1980-1989 ${ }^{45}$

(en porcentaje de la PEA de cada grupo obrero)

\begin{tabular}{l|c|c|c|c|c|c}
\hline Grupo mineria & $\mathbf{1 9 8 0}$ & $\mathbf{1 9 8 2}$ & $\mathbf{1 9 8 6}$ & $\mathbf{1 9 8 7}$ & $\mathbf{1 9 8 8}$ & $\mathbf{1 9 8 9}$ \\
\hline Gran Mineria Cobre & 20,95 & 26,10 & 7,48 & 6,88 & 8,24 & 13,73 \\
\hline PYME Cobre & 32,18 & 34,31 & 30,32 & 33,77 & 33,79 & 34,41 \\
\hline Otros & 46,87 & 39,59 & 62,20 & 59,36 & 57,97 & 51,85 \\
\hline Total & $\mathbf{1 0 0 , 0}$ & $\mathbf{1 0 0 , 0}$ & $\mathbf{1 0 0 , 0}$ & $\mathbf{1 0 0 , 0}$ & $\mathbf{1 0 0 , 0}$ & $\mathbf{1 0 0 , 0}$ \\
\hline Grupo industria y construcción & & & & & & \\
\hline Industria Tradicional & 45,93 & 50,73 & 46,17 & 44,40 & 42,20 & 42,49 \\
\hline Industria Sustitutiva & 20,22 & 19,30 & 22,17 & 22,47 & 24,47 & 23,88 \\
\hline Construcción & 24,85 & 17,82 & 27,02 & 28,24 & 29,87 & 30,46 \\
\hline Asalariados públicos de la industria & 9,01 & 12,16 & 4,64 & 4,89 & 3,46 & 3,16 \\
\hline Total & $\mathbf{1 0 0 , 0}$ & $\mathbf{1 0 0 , 0}$ & $\mathbf{1 0 0 , 0}$ & $\mathbf{1 0 0 , 0}$ & $\mathbf{1 0 0 , 0}$ & $\mathbf{1 0 0 , 0}$ \\
\hline Grupo comercio y servicio & & & & & & \\
\hline Comerción & 13,76 & 13,78 & 6,77 & 6,25 & 5,02 & 3,78 \\
\hline Transporte & 25,97 & 23,60 & 21,08 & 21,16 & 20,70 & 21,76 \\
\hline Servicio & 14,40 & 15,67 & 32,35 & 31,84 & 31,38 & 31,34 \\
\hline Oficina & 29,99 & 30,79 & 28,34 & 30,35 & 31,48 & 31,12 \\
\hline Sector Público & 15,89 & 16,16 & 11,47 & 10,40 & 11,42 & 11,99 \\
\hline Total & $\mathbf{1 0 0 , 0}$ & $\mathbf{1 0 0 , 0}$ & $\mathbf{1 0 0 , 0}$ & $\mathbf{1 0 0 , 0}$ & $\mathbf{1 0 0 , 0}$ & $\mathbf{1 0 0 , 0}$ \\
\hline & & & & & \\
\hline
\end{tabular}

Fuente: Elaboración propia.

45Son empresas productoras de cobre de la gran minería las que produzcan, dentro del país, cobre "blíster", refinado a fuego o electrolítico, en cantidades no inferiores a 75.000 toneladas métricas anuales mediante la explotación y beneficio de minerales de producción propia o de sus filiales o asociados (Ley 18.940). No es posible desagregar con este nivel de detalle los datos ocupacionales del año 1971. 
En 1980-1989 los trabajadores de la industria tradicional disminuyen su peso interno desde un 45,9 a 42,5\% y de los asalariados públicos de la industria del 9,0 al 3,2 (Cuadro 2). Precisamente, las ramas industriales tradicionales son las que menos condiciones económicas tiene para competir con la abrupta apertura económica que impulsa la dictadura, en tanto el declive de los obreros de las empresas públicas se explica por las privatizaciones del periodo. Los obreros de la industria sustitutiva, cuyos oligopolios estatales son traspasados a grupos económicos locales, incrementan su peso relativo producto de la recuperación económica que se registra desde 1986. De todos modos, esta privatización forzada los aleja de la seguridad social y de los beneficios laborales típicos del empleo público. En adelante, estos obreros industriales se reincorporan en peores condiciones laborales y en procesos de trabajo mucho más flexibilizados debido a las transformaciones productivas que experimenta la industria chilena $^{46}$. No obstante, el sector que mayor peso alcanza dentro de la clase obrera industrial son los trabajadores de la construcción que entre 1980 y 1989 aumentan su participación relativa de 24,9 a $30,5 \%$.

Estos cambios no son solo cuantitativos, sino que impactan en la configuración social, política y cultural de la clase obrera nacional. La disminución de los obreros de la industria tradicional y la privatización de aquellos vinculados a los sectores estratégicos, alteran la fisonomía de los trabajadores manuales. Unos quedan desempleados, otros deben reconvertirse en actividades por cuenta propia o bien aceptar condiciones mucho más flexibles y desprotegidas de trabajo. Son una generación completa de obreros que pierden derechos laborales alcanzados tras décadas de movilización y que registran escasas posibilidades de reconversión laboral; en tanto, los aparatos de propaganda de la dictadura y la nueva ideología del emprendimiento contribuyen a naturalizar condiciones de flexibilidad y precariedad en los nuevos trabajadores. Por otro lado, la expansión de los trabajadores de la construcción avanza de la mano de una mayor inversión en obras públicas y de edificios para la instalación de oficinas comerciales y viviendas que se expande luego de la crisis. Pero su tradición sindical más corporativa y su naturaleza nómada dificultan su constitución como fuerza gravitante en la dirección del conjunto de los trabajadores manuales asalariados, como lo fueron antaño los obreros industriales.

Los trabajadores del sector terciario representan la fracción de mayor peso y expansión dentro de la clase obrera, lo que modifica la configuración obrera alcanzada hasta 1973. En 1980-1989 la fisonomía obrera se constituye con base en el trabajo no manual, particularmente aquel demandado por la rama de servicios (14,4 a 31,4\%) y las oficinas privadas (de 30,0 a $31,1 \%$ ), en que también se desenvuelven franjas medias de la burocracia de servicios ${ }^{47}$. Pese a su escasa calificación, estos "obreros de servicio" participan en ocupaciones vinculadas con dinámicas de producción más próximas al nuevo patrón de acumulación neoliberal. Específicamente, el acceso a empleos de "cuello blanco" y administración genera en estos asalariados una percepción de integración a procesos de trabajo que desde un inicio registran importantes niveles de flexibilidad, de allí que la valoración de tales condiciones sea radicalmente distinta a aquellos antiguos trabajadores que provienen de la industria o del empleo público. Aunque sea de forma periférica, estos nuevos asalariados se insertan en

46Cecilia Montero, La revolución empresarial chilena, Santiago, Cieplan, Dolmen Ediciones, 1997.

47Ruiz y Boccardo, op. cit. 
procesos de modernización, sobre todo cuando acceden a un nivel de consumo ${ }^{48}$ inédito si se compara con el alcanzado por sus padres, cuyas ocupaciones estuvieron por lo general vinculadas con la industria o la agricultura, o si se compara con la experiencia de vida que registran estos trabajadores durante la crisis económica de los años setenta y ochenta.

A finales de los años ochenta se registra una recuperación parcial del empleo industrial, sin embargo, esto no implica una recuperación cualitativa de la clase obrera industrial. Por el contrario, las trayectorias que predominan se relacionan con cursos de terciarización que integra a trabajadores no manuales con cierto grado de calificación con otros cuyas habilidades laborales se reducen a la ejecución de tareas de rutina en oficinas, servicios o el comercio ${ }^{49}$. La clave es que ambos grupos de trabajadores terciarios, calificados y no calificados, participan diferenciadamente de la misma cadena de valor, relativizándose nociones como la marginalidad vinculada históricamente con formas de desarrollo periférico en que existía una proporción considerable de trabajadores no manuales que quedaba excluido producto de las incapacidades del propio modelo productivo.

En definitiva, se desarrolla un creciente distanciamiento entre estos nuevos asalariados, manuales y no manuales, respecto de la cultura obrera industrial forjada hasta 1973. Los viejos referentes sindicales dejan de convocar a la mayoría de los trabajadores asalariados, en tanto la vía individual de "integración" mediante el consumo y el endeudamiento mina las posibilidades futuras de acción colectiva. Sin embargo, tales transformaciones no se explican únicamente por trayectorias de cambio estructural ni son un todo inevitable. Por el contrario, son las variantes concretas en que las fuerzas políticas resuelven la transición a la democracia lo que condiciona el retorno de la vieja clase obrera industrial, pero también de las posibilidades de organización de los nuevos asalariados en el comercio y los servicios.

\section{Los sindicatos ante la transición: rearticulación sin los obreros industriales}

El agotamiento de las protestas hacia 1985 y el fallido atentado al general Pinochet en 1986, fortalecen las posiciones que alientan una salida pactada con la dictadura ${ }^{50}$. Efectivamente, adquiere fuerza la alianza entre los sectores más conservadores de la DC con las fracciones renovadas del PS articulados desde 1983 en la Alianza Democrática. Pese a las diferencias que existen con los miembros del Movimiento Democrático Popular, integrado principalmente por comunistas y el resto de los socialistas, a nivel sindical se confluye en torno a la nueva Central Unitaria de Trabajadores (CUT) en 1988.

El CNT y la CNS convocan a una Conferencia Nacional en que se analizan diversos problemas para sentar las bases de un nuevo sindicalismo en democracia que amplíe la convocatoria social a franjas asalariadas que históricamente no habían sido parte de los sindicatos $^{51}$. El proceso constituyente de la nueva CUT decantó en una carta de principios contraria a la explotación en el trabajo, la defensa de una democracia sustantiva y el reconocimiento de derechos económicos y sociales, pero sin mencionar una vinculación

48Moulian, op. cit.

49Ruiz y Boccardo, op. cit.

50Rafael Otano, Nueva crónica de la transición, Santiago, Lom Ediciones, 2006.

51Araya, op. cit. 
directa con un proyecto político específico ${ }^{52}$. Se trataba de un intento por equilibrar el nuevo ideario demócrata cristiano y de la renovación socialista que rechazaban una definición clasista de la central, con los principios del "socialismo almeydista" y de comunistas que entendían como indisoluble la defensa de los trabajadores con la lucha de clases.

Las elecciones de las directivas de la Central Unitaria de Trabajadores, la Asociación Nacional de Empleados Fiscales y del Colegio de Profesores, arrojaron en las presidencias a dirigentes demócrata cristianos que, con el apoyo de socialistas renovados, se unen activamente a la campaña por el No en el Plebiscito de 1988 y a la candidatura del DC Patricio Aylwin en 1989. De todas formas, su programa de gobierno mostraba una voluntad explícita de introducir cambios profundos en la institucionalidad laboral de 1979 de modo de restituir derechos fundamentales de los trabajadores y fortalecer a las organizaciones sindicales ${ }^{53}$. Pero más allá de las intenciones, la nueva política de los acuerdos con base en el modelo neoliberal y el temor a una regresión autoritaria sepultaron cualquier posibilidad de reformas sustantivas en materia laboral.

La renovación ideológica que se impone en las conducciones de la DC y el PS, además de la exclusión del PC de la institucionalidad política, impiden un retorno a idearios más obreristas y combativos. De hecho, las tradiciones modernizantes y nacional populares encabezadas por demócrata cristianos y socialistas en los gobiernos de Frei y Allende, fueron silenciados eficazmente durante la formación de la alianza que funda la Concertación de Partidos por la Democracia en 1988. En la década del noventa se instala una modernización neoliberal en que no caben los intereses sociales de la clase obrera pero tampoco los de la clase media desarrollista, que habías sido fundamentales en la formación y desenvolvimiento de los proyectos históricos de la DC y el PS ${ }^{54}$.

En adelante, los ideólogos de la Concertación proclama el fin definitivo de las luchas de clases y el inicio de una nueva era de consensos ${ }^{55}$. En ese sentido, el declive la clase obrera chilena no es sólo imputable a las reformas que impulsa la dictadura y a los cursos de acción de las organizaciones obreras en ese periodo. Pese a la debacle estructural que experimentan, a fines de los ochenta todavía existe espacio para una recuperación de la industria y de sus trabajadores ${ }^{56}$. Sin embargo, ya en el gobierno de Aylwin se traza un derrotero que profundizará el legado neoliberal de los militares en la década del noventa: continuidad de la institucionalidad política alcanzada durante la transición; una economía abierta basada en el estímulo a la industria primario exportadora en detrimento de otra orientada a la producción para el mercado interno; la privatización de los servicios sociales y una política de gasto social focalizada ${ }^{57}$.

Con el retorno de la democracia la clase obrera chilena no se rearticula. Es cierto que el marco legal heredado y las transformaciones productivas lo dificultan. Efectivamente, las tasas de sindicalización no se recuperan ${ }^{58}$ y la configuración de pequeños sindicatos organizados en

52Francisco Zapata, "Transición democrática y sindicalismo en Chile”, Foro Internacional, 130, 1992, 703-721.

53Programa de gobierno: Concertación de Partidos por la Democracia, 1989.

54 Carlos Ruiz, De nuevo la sociedad, Santiago, LOM Ediciones, 2015.

55Op. cit. 5.

56Díaz, op. cit.

57Ruiz y Boccardo, op. cit.

58La tasa de sindicalización de los trabajadores dependientes fue 16,1\% en el año 2008; 17,3\% en 2009 y $15,8 \%$ en 2010 . En Dirección del Trabajo, Compendio de series estadísticas. 1990-2011, Santiago, Departamento de Estudios, 2011. 
torno a cada empresa, tienen escasa capacidad de negociación frente a los empleadores. En tanto, las sucesivas reformas laborales y el accionar de los partidos de la Concertación hunden a las organizaciones sindicales que sobreviven a la dictadura y a sus transformaciones ${ }^{59}$. Los sindicatos tradicionales, cuyo principal referente sigue siendo la CUT, pierden crecientemente peso, quedando reducidas al ámbito del empleo público, aunque mantienen cierta capacidad de presión, más por las vinculaciones políticas de sus dirigentes que por la fuerza de sus movilizaciones.

En definitiva, el derrotero seguido en los años noventa por las organizaciones sindicales se desanclará crecientemente de los nuevos trabajadores asalariados, mayoritariamente ocupados en las ramas de servicios, en parte por las transformaciones estructurales, pero también por el carácter socialmente excluyente que asume la transición y los partidos políticos que antaño habían organizado social y políticamente a la clase obrera chilena.

\section{Bibliografía}

Sergio Aranda y Alberto Martínez, "Estructura Económica: algunas características fundamentales", CESO, Chile, hoy, Santiago, Siglo XXI Editores, 1970, 55-172.

Rodrigo Araya, "Ha llegado la hora de decir basta. El movimiento sindical y la lucha por la democracia en Chile, 1973-1990”, Izquierdas, 27, diciembre 2017, 191-211.

Alberto Armstrong y Beiza Águila, Evolución del conflicto laboral en Chile: 1961-2002, Santiago, Ediciones Universidad Católica de Chile, 2006.

Alan Angell, Partidos políticos y movimiento obrero en Chile, México D.F., Ediciones Era, 1974.

Rodrigo Baño, "Más allá de culpas y buenas intenciones", Rodrigo Baño, Unidad Popular 30 años después, Santiago, Lom Ediciones, 2003, 291-318.

Giorgio Boccardo, "Trabajo y el ocaso de la izquierda histórica en Chile", Cuadernos de Coyuntura, Fundación Nodo XXI, 2015, 17-27.

Giorgio Boccardo, "Cambios recientes en la estructura social de Argentina, Brasil y Chile 1980-2010)", Entramados y perspectivas, 2, 2014, 43-70.

José Joaquín Brunner, Bienvenidos a la modernidad, Santiago, Editorial Planeta, 1994.

Guillermo Campero, "El sindicalismo chileno en el régimen militar (1973-1984)", Ibero-Americana: Nordic Journal of Latin American Studies, 14, 1985, 1-2.

René Cortázar, "Políticas de reajustes y salarios en Chile: 1974-1982”, Colección Estudios, Cieplan, 10, 1983, 45-64;

59Giorgio Boccardo, "Trabajo y el ocaso de la izquierda histórica en Chile”, Cuadernos de Coyuntura, Fundación Nodo XXI, 2015, 17-27. 
Álvaro Díaz, "La reestructuración industrial autoritaria en Chile”, Revista Proposiciones, 17, 1989, 1435.

Dirección del Trabajo, Compendio de series estadísticas. 1990-2011, Santiago, Departamento de Estudios, 2011.

Torcuato Di Tella y Alain Touraine, Huachipato et Lota. Étude sur la conscience ouvrière dans deux entreprises chiliennes, París, Centre National de la Recherche Scientifique de Paris (CNRS), 1966.

Paul Drake, "El movimiento obrero en Chile: De la Unidad Popular a la Concertación" Revista de Ciencia Política (Santiago), 23:2, 2003, 148-158.

Enzo Faletto, "La dependencia y lo nacional-popular", Nueva Sociedad, 40, enero-febrero 1979, 40-49.

Enzo Faletto y Eduardo Ruiz, Conflicto político y estructura social, CESO, Chile, hoy, Santiago, Siglo XXI Editores,

Patricio Frías, El Trabajo ¿ Servidumbre o realización?, Santiago, Ediciones Radio Universidad de Chile, 2017.

Alejandro Foxley, "Hacia una economía de libre mercado: 1974-1979”, Revista de Estudios, Cieplan, 4, 1981, 5-37.

Franck Gaudichaud, Chile 1970-1973. Mil dias que estremecieron al mundo, Barcelona, Editorial Sylone, 2017.

Sergio Grez, De la "regeneración del pueblo" a la buelga general: génesis y evolución histórica del movimiento popular en Chile (1810-1890), Santiago, RIL Editores, 2007.

Dasten Julián, "Tendencias de un sindicalismo fracturado. Sindicalismo autoritario v/s sindicalismo movimientista”, Actuel Marx Intervenciones, 13, 2012, 95-113.

Ana López, "El mundo del trabajo entre el disciplinamiento y la resistencia, Chile, 1973-1981", Procesos. Revista ecuatoriana de historia, 44, 2016, 75-101.

Oscar Mac-Clure, “La acción reivindicativa sindical en Chile”, Proposiciones, 17, 1989, 110-123.

Cecilia Montero, La revolución empresarial chilena, Santiago, Cieplan, Dolmen Ediciones, 1997.

Tomás Moulian, Chile actual: Anatomía de un mito, Santiago, Lom Ediciones, 1997.

Rafael Otano, Nueva crónica de la transición, Santiago, Lom Ediciones, 2006.

José Piñera, La revolución laboral en Chile, Santiago, Zig-Zag, 1992.

Irene Rojas, "Las reformas laborales al modelo normativo de negociación colectiva del Plan Laboral", Ius et Praxis, Talca, 13:2, 2007, 195-221.

Carlos Ruiz, De nuevo la sociedad, Santiago, Lom Ediciones, 2015. 
Carlos Ruiz, "Reseña del libro de Eugenia Palieraki ¡La Revolución ya viene! El MIR chileno de los años sesenta", Actuel Marx Intervenciones, 2015, 211-218.

Ruiz Carlos y Giorgio Boccardo, Los chilenos bajo el neoliberalismo. Clases y conflicto social, Santiago, El Desconcierto-Fundación Nodo XXI, 2014.

Eugenio Tironi, La irrupción de las masas y el malestar de las elites. Chile en el cambio de siglo, Santiago, Editorial Grijalbo, 1999.

Eugenio Tironi y Javier Martínez, "Las clases sociales en Chile; cambio y estratificación 1970-1980", Santiago, Ediciones Sur, 1985.

Ángela Vergara , "Conflicto y modernización en la Gran Minería del Cobre (1950-1970)", Historia, Santiago, 37:2, 2004, 419-436.

Peter Winn, “El Taylorismo y la gran huelga de Yarur de 1962”, Proposiciones, 19, 1990, 202-222.

Francisco Zapata, "Transición democrática y sindicalismo en Chile", Foro Internacional, 130, 1992, 703-721.

Francisco Zapata, Clases sociales y acción obrera en Chile, México D.F., Colegio de México, Centro de Estudios Sociológicos, 110, 1986.

\section{Documentos}

Informe Comisión Nacional sobre Prisión Política y Tortura, Santiago, 2004.

Ley No 18.940, 23 de febrero de 1990. Recuperado de: https://www.bcn.cl/historiadelaley/nc/historiade-la-ley/7315/

Programa de gobierno: Concertación de Partidos por la Democracia, 1989.

\section{Base de Datos}

Encuesta Nacional de Empleo (ENE), trimestre octubre-diciembre, del Instituto Nacional de Estadísticas (INE), 1982, 1986, 1987, 1988, 1989.

\section{Revistas}

Entrevista a José Villegas, Presidente Sindicato Colbún-Machicura, en Revista Apsi, 117, 25 de enero al 7 de febrero, 1983, 8. 